\title{
Tumour mutation status and sites of metastasis in patients with cutaneous melanoma
}

\author{
Nikki R Adler ${ }^{\star, 1,2}$, Rory Wolfe ${ }^{2}$, John W Kelly ${ }^{1}$, Andrew Haydon ${ }^{1,3}$, Grant A McArthur ${ }^{4,5}$, Catriona A McLean ${ }^{1,6}$ \\ and Victoria J Mar ${ }^{1,2,7}$ \\ ${ }^{1}$ Victorian Melanoma Service, Alfred Hospital, Melbourne, Victoria 3004, Australia; ${ }^{2}$ School of Public Health and Preventive \\ Medicine, Monash University, Melbourne, Victoria 3004, Australia; ${ }^{3}$ Department of Medical Oncology, Alfred Hospital, Melbourne, \\ Victoria 3004, Australia; ${ }^{4}$ Divisions of Research and Cancer Medicine, Peter MacCallum Cancer Centre, Melbourne, Victoria 3000, \\ Australia; ${ }^{5}$ Sir Peter MacCallum Department of Oncology, University of Melbourne, Victoria 3000, Australia; ${ }^{6}$ Department of \\ Anatomical Pathology, Alfred Hospital, Melbourne, Victoria 3004, Australia and ${ }^{7}$ Skin and Cancer Foundation, Carlton, Victoria \\ 3053, Australia
}

Background: Cutaneous melanoma can metastasise haematogenously and/or lymphogenously to form satellite/in-transit, lymph node or distant metastasis. This study aimed to determine if BRAF and NRAS mutant and wild-type tumours differ in their site of first tumour metastasis and anatomical metastatic pathway.

Methods: Prospective cohort of patients with a histologically confirmed primary cutaneous melanoma at three tertiary referral centres in Melbourne, Australia from 2010 to 2015. Multinomial regression determined clinical, histological and mutational factors associated with the site of first metastasis and metastatic pathway.

Results: Of 1048 patients, 306 (29\%) developed metastasis over a median 4.7 year follow-up period. 73 (24\%), 192 (63\%) and 41 (13\%) developed distant, regional lymph node and satellite/in-transit metastasis as the first site of metastasis, respectively. BRAF mutation was associated with lymph node metastasis (adjusted RRR $2.4695 \% \mathrm{Cl} 1.07-5.69, P=0.04$ ) and sentinel lymph node positivity (adjusted odds ratio [aOR] OR 1.55, 95\% Cl 1.14-2.10, $P=0.005$ ). BRAF mutation and NRAS mutation were associated with increased odds of developing liver metastasis (aOR 3.09,95\% Cl 1.49-6.42, $P=0.003$; aOR 3.17, 95\% Cl 1.32-7.58, $P=0.01$ ) and central nervous system (CNS) metastasis (aOR 4.65, 95\% Cl 2.23-9.69, $P<0.001$; aOR 4.03, 95\% Cl 1.72-9.44, $P=0.001$ ). NRAS mutation was associated with lung metastasis (aOR 2.44, 95\% Cl 1.21-4.93, $P=0.01$ ).

Conclusions: BRAF mutation was found to be associated with lymph node metastasis as first metastasis and sentinel lymph node positivity. BRAF and NRAS mutations were associated with CNS and liver metastasis and NRAS mutation with lung metastasis. If these findings are validated in additional prospective studies, a role for heightened visceral organ surveillance may be warranted in patients with tumours harbouring these somatic mutations.

Recent advances in melanoma treatment have led to more intensive surveillance of high-risk patients as there is evidence to suggest that certain treatments are more effective in patients with low volume metastatic disease (Hodi et al, 2010; Sosman et al, 2012; Ribas et al, 2016). An improved understanding of the pathways of metastatic disease, including the clinicopathological

*Correspondence: Dr N Adler; E-mail: Nikki.adler@monash.edu

Received 6 April 2017; revised 13 June 2017; accepted 7 July 2017; published online 8 August 2017

(C) 2017 Cancer Research UK. All rights reserved 0007-0920/17 
factors that influence these pathways, is important to improve surveillance strategies and to individualise follow-up of high-risk patients.

Cutaneous melanoma can metastasise haematogenously and/or by the lymphatic system (Mervic, 2012). Cutaneous melanoma can metastasise as satellite or in-transit metastasis, lymph node metastasis or distant metastasis (Meier et al, 2002; Leiter et al, 2004). Satellite metastasis has been defined as the development of metastatic nodules within two centimetres of the primary tumour, while in-transit metastasis has been defined as the development of metastasis within the dermal and subdermal lymphatics in the drainage area before the first regional lymph node basin (Meier et al, 2002; Leiter et al, 2004). Satellite, in-transit and regional lymph node metastasis represents locoregional disease. Approximately two-thirds of patients who develop metastasis initially present with locoregional disease, while one-third present with distant metastasis (Reintgen et al, 1992; Soong et al, 1998; CohnCedermark et al, 1999; Meier et al, 2002; Tejera-Vaquerizo et al, 2007). Nonetheless, there has been limited research investigating the clinicopathological factors associated with the pathways of progression in patients with primary cutaneous melanoma.

It is well-recognised that $40-50 \%$ and $15 \%$ of cutaneous melanomas harbour activating mutations of BRAF and NRAS, respectively (Smalley, 2003; Hocker \& Tsao, 2007; Liu et al, 2007; Devitt et al, 2011; Long et al, 2011). Mutations in BRAF and NRAS oncogenes are associated with distinct phenotypic and histopathological characteristics (Ellerhorst et al, 2011; Long et al, 2011; Colombino et al, 2012; Hodis et al, 2012; Barbour et al, 2014). The relationship between tumour mutation status and the metastatic pathways of progression is not yet understood.

The primary aim of this study was to determine if $B R A F$ and NRAS mutant tumours compared to wild-type tumours have a propensity to metastasise as satellite/in-transit, regional lymph node or distant metastasis as the first site of metastasis and if these tumours behave differently in their anatomical metastatic pathways. We also aimed to investigate the relationship between clinicopathological characteristics and the anatomical pathways of disease progression. A secondary aim was to determine if the time course to the development of distant metastasis depends on these anatomical metastatic pathways.

\section{MATERIALS AND METHODS}

This was a prospective cohort study of participants in the Melbourne Melanoma Project (MMP). Patients referred to one of three tertiary referral centres in Melbourne, Australia (Victorian Melanoma Service at The Alfred Hospital, Peter MacCallum Cancer Centre and the Olivia Newton-John Cancer Research Institute at the Austin Hospital) with a histologically confirmed primary cutaneous melanoma were eligible for enrolment in the MMP. Patients were enroled within 6 months of presentation to the abovementioned institutions between 2010 and 2015. The majority of patients (84\%) had stage I/II disease at diagnosis. Patients with uveal melanoma, mucosal melanoma or melanoma of unknown primary site were excluded. Patients with multiple invasive primary melanomas and patients with in situ melanoma were excluded. Institutional ethics approval was obtained from the contributing sites (project number 07/38). Written and verbal consent was obtained from all patients.

Clinical, pathological and molecular characteristics were prospectively recorded. The primary melanomas of $73 \%$ of all patients enroled in MMP were tested for the presence of a BRAF and NRAS mutation. Patients without $B R A F$ and NRAS mutation testing were excluded. Mutational testing was performed at the Department of Anatomical Pathology, Alfred Hospital, Melbourne, Australia or the Department of Diagnostic Molecular Pathology, Peter MacCallum Cancer Centre, Melbourne, Australia. Hematoxylin and eosin-stained sections of formalin-fixed, paraffin-embedded tissue were reviewed by a pathologist, followed by macrodissection to ensure the percentage of tumour cells was enriched to at least $30 \%$. DNA was then extracted from each sample and checked for adequate concentration. Matrix assisted laser desorption ionisation time-of-flight mass spectrometry was used for mutational analyses. DNA quality was evaluated via Eppendorf spectrophotometer. The sample was checked for multiple known mutations in $B R A F$ (exon 11 and 15), NRAS (exon 2, 3 and 4) and KIT (exon 11, 13 and 17) using Sequenom (Agena) Mass ARRAY OncoFocus panel (Version 3).

Clinical variables recorded by the treating doctor at the patients' initial presentation included: age, sex, phenotypic markers (eye colour, hair colour and skin phototype) and personal history of melanoma.

The tumour characteristics that were collected in MMP included: date of diagnosis, anatomical location of the primary tumour, Breslow thickness (mm), Clark level, histologic subtype, mitotic rate $\left(n / \mathrm{mm}^{2}\right)$ and ulceration. Tumour histologic subtype was classified according to the current World Health Organization classification system. We included patients with superficial spreading melanoma (SSM), nodular melanoma (NM) and lentigo maligna melanoma (LMM). Patients with acral lentiginous melanoma, desmoplastic melanoma and other less common subtypes, including naevoid, balloon cell, spindle cell and Spitzoid melanoma, were excluded. The anatomical location of the primary tumour was classified as upper extremity, lower extremity, head and neck region, or trunk.

Patients were followed up as per routine care by one of the tertiary institutions listed above or by community doctors (i.e., general practitioners or specialists), depending on their stage and disease progression. Postal questionnaires seeking information on disease recurrence were sent to community doctors annually. Patients' disease progression was prospectively recorded. The date and site of detected metastasis and the mode of detection (clinical or radiological) were recorded. Radiologic detection included computed tomography, positron emission tomography, magnetic resonance imaging or ultrasound. The details were recorded for the initial site of metastasis as well as for all subsequent recurrences. The date of death was recorded for all participant deaths and the cause of death was recorded as either due to melanoma, another malignancy or other cause. Notification of death was from community doctors, hospital medical records, 'deceased, return to sender' letters or family correspondence.

Four distinct metastatic routes to the development of distant metastasis were used in our analysis, which have been described by Meier et al (2002). These included: 1-development of satellite or intransit metastases followed by regional lymph node metastases and distant metastases, 2-development of satellite or in-transit metastases followed by distant metastases, 3-development of regional lymph node metastases followed by distant metastases and 4-development of distant metastases as first tumour recurrence (Meier et al, 2002).

All statistical analyses were performed using Stata version 14.2 (StataCorp LP, College Station, TX, USA) statistical software. Breslow thickness was analysed as a categorical variable $(<1.00 \mathrm{~mm}, 1.0-2.0 \mathrm{~mm}, 2.01-4.0 \mathrm{~mm},>4.01 \mathrm{~mm})$ and age was dichotomised as less than or greater than 50 years. Univariate and multivariate multinomial regression analyses were conducted to compare various clinical and pathological variables between patients with BRAF mutations, NRAS mutations and BRAF/NRAS wild-type tumours with the associations summarised as relative risk ratios (RRR) and 95\% confidence intervals (CI). Univariate and multivariate multinomial regression analyses were conducted to describe associations of clinical, histological and mutational 
factors with the site of first metastasis and the anatomical pathways of progression. Logistic regression was used to assess associations of various clinicopathological characteristics with BRAF V600E and $\mathrm{V} 600 \mathrm{~K}$ mutational subtypes and with sentinel lymph node positivity, summarised as odds ratios (OR). Statistical significance was defined as a p-value less than 0.05. Melanoma-specific survival (MSS) was compared between patients with BRAF mutant, NRAS mutant and wild-type tumours. Multivariate Cox proportional hazards regression was performed to estimate associations with survival.

\section{RESULTS}

The MMP cohort included 1955 patients with clinical and histologic data who had a new diagnosis of cutaneous melanoma between 2010 and 2015. We excluded 192 patients with a single primary in situ melanoma, 219 patients with multiple invasive primary melanomas and 106 patients with less common melanoma subtypes. Of the remaining 1438 patients, 390 patients were excluded as they did not have BRAF and NRAS mutation testing of their tumours. Thus, 1048 patients were included in the analyses for this study.

Descriptive statistics. The median age at diagnosis was 58 years (range 20-90 years) and 58\% of participants were male. Further, 360 (34.7\%) melanomas were located the trunk, 251 (24.2\%) on the upper extremity, $220(21.2 \%)$ on the head and neck and 206 (19.9\%) on the lower extremity. The median Breslow thickness was $1.6 \mathrm{~mm}$ (IQR $0.8-3.0 \mathrm{~mm}$ ). The median mitotic rate was 2 mitoses per $\mathrm{mm}^{2}$ (IQR $0-6$ per $\mathrm{mm}^{2}$ ) and $28 \%$ of tumours were ulcerated.

Tumour mutation frequencies. Among the 1048 primary melanomas, $48.6 \%$ were BRAF mutant, $19.0 \%$ were NRAS mutant and $32.4 \%$ were $B R A F / N R A S$ wild type. Among the BRAF mutant tumours, the most common genotype was V600E (70.0\%), followed by V600K (24.2\%) and less common genotypes (5.8\%). The majority (93.2\%) of NRAS mutant tumours had an NRAS codon 61 mutation.

Tumour mutation status and clinicopathological correlations. Clinical and pathological characteristics are described by BRAF and NRAS mutation status in Table 1 with corresponding estimates of associations presented in Table 2. Median age differed between patients with BRAF mutant, NRAS mutant and BRAF/NRAS wildtype tumours (53 vs 62 vs 61 years, respectively). Even when adjusted for other factors, compared to those aged $>50$ years, patients aged $<50$ years had 2.48-fold higher relative risk of having a BRAF mutant tumour than a BRAF/NRAS wild-type tumour and a 3.59-fold higher relative risk of having a $B R A F$ mutant tumour than a NRAS mutant tumour (RRR 2.48, 95\% CI 1.82-3.38, $P<0.001$; RRR 3.59, 95\% CI 2.39-5.41, $P<0.001$, respectively). Compared to $B R A F / N R A S$ wild-type tumours, $B R A F$ mutation was associated with truncal location and superficial spreading subtype after adjustment for other variables (Tables 1 and 2).

Compared to BRAF mutations, NRAS mutations were more common in tumours on the upper extremities (adjusted RRR (aRRR) 2.38, 95\% CI 1.38-4.10, $P=0.002$ ) and lower extremities (aRRR $1.7795 \%$ CI $1.02-3.09, P=0.04$ ) than the head and neck region.

Compared to patients with BRAF V600E mutant tumours, patients with $B R A F$ V600K mutant tumours had an increased odds of being male (OR 2.04, 95\% CI 1.33-3.19, $P<0.001$ ), older (OR $\geqslant 50$ years $6.38,95 \%$ CI $3.78-10.79, P<0.001)$ and having tumours located on the head and neck region compared to the trunk (RR 2.45, 95\% CI 1.42-4.22, $P=0.001)$. When adjusted for
Table 1. Clinical and pathological characteristics according to BRAF and NRAS mutation status

\begin{tabular}{|c|c|c|c|}
\hline $\begin{array}{l}\text { Clinicopathological } \\
\text { variable }\end{array}$ & $\begin{array}{c}\text { BRAF mutant } \\
(\%)\end{array}$ & $\begin{array}{c}\text { NRAS mutant } \\
(\%)\end{array}$ & $\begin{array}{l}\text { WT/WT } \\
(\%)\end{array}$ \\
\hline Total number & 509 (48.6) & 199 (19.0) & $340(32.4)$ \\
\hline $\begin{array}{l}\text { Patient sex } \\
\text { Males } \\
\text { Females }\end{array}$ & $\begin{array}{l}278(45.4) \\
231(53.0)\end{array}$ & $\begin{array}{r}118(19.3) \\
81(18.6)\end{array}$ & $\begin{array}{l}216(35.3) \\
124(28.4)\end{array}$ \\
\hline $\begin{array}{l}\text { Patient age } \\
<50 \text { years } \\
\geqslant 50 \text { years }\end{array}$ & $\begin{array}{l}216(65.8) \\
290(40.6)\end{array}$ & $\begin{array}{r}34(10.4) \\
164(23.0)\end{array}$ & $\begin{array}{r}78(23.8) \\
260(36.4)\end{array}$ \\
\hline $\begin{array}{l}\text { Anatomical location } \\
\text { Head \& neck } \\
\text { Trunk } \\
\text { Upper extremity } \\
\text { Lower extremity }\end{array}$ & $\begin{array}{r}94(42.7) \\
207(57.5) \\
98(39.0) \\
104(50.5)\end{array}$ & $\begin{array}{l}25(11.4) \\
60(16.7) \\
62(24.7) \\
49(23.8)\end{array}$ & $\begin{array}{r}101(45.9) \\
93(25.8) \\
91(36.3) \\
53(25.7)\end{array}$ \\
\hline $\begin{array}{l}\text { Breslow thickness } \\
\quad<1.0 \mathrm{~mm} \\
1.00-2.0 \mathrm{~mm} \\
2.01-4.0 \mathrm{~mm} \\
>4.01 \mathrm{~mm}\end{array}$ & $\begin{array}{r}175(50.7) \\
142(51.1) \\
113(43.6) \\
73(47.7)\end{array}$ & $\begin{array}{l}37(10.7) \\
71(25.5) \\
62(23.9) \\
26(17.0)\end{array}$ & $\begin{array}{r}133(38.6) \\
65(23.4) \\
84(32.4) \\
54(35.3)\end{array}$ \\
\hline $\begin{array}{l}\text { Histologic subtype } \\
\text { SSM } \\
\text { NM } \\
\text { LMM }\end{array}$ & $\begin{array}{r}346(52.3) \\
129(46.6) \\
14(23.3)\end{array}$ & $\begin{aligned} 125 & (18.9) \\
57 & (20.6) \\
5 & (8.3)\end{aligned}$ & $\begin{array}{r}190(38.7) \\
91(32.9) \\
41(68.3)\end{array}$ \\
\hline $\begin{array}{l}\text { Mitotic rate }\left(\mathrm{n} / \mathrm{mm}^{2}\right) \\
\quad<5 \\
5-9 \\
\geqslant 10\end{array}$ & $\begin{array}{r}334(48.9) \\
92(47.9) \\
78(48.2)\end{array}$ & $\begin{array}{r}119(17.4) \\
45(23.4) \\
32(19.8)\end{array}$ & $\begin{array}{r}230(33.7) \\
55(28.7) \\
52(32.1)\end{array}$ \\
\hline $\begin{array}{l}\text { Ulceration } \\
\text { No } \\
\text { Yes }\end{array}$ & $\begin{array}{l}346(48.3) \\
147(50.3)\end{array}$ & $\begin{array}{r}130(18.2) \\
60(20.6)\end{array}$ & $\begin{array}{r}240(33.5) \\
85(29.1)\end{array}$ \\
\hline
\end{tabular}

Abbreviations: $\mathrm{LMM}=$ lentigo maligna melanoma; $\mathrm{NM}=$ nodular melanoma; $\mathrm{SSM}=$ superficial spreading melanoma; WT = wild type.

confounders, the relationship between BRAF V600K mutation and older age (aOR 5.93, 95\% CI 3.43-10.27, $P<0.001)$ and with head and neck location (aOR 2.16, 95\% CI 1.16-4.01, $P=0.015$ ) remained. The association between V600K mutation and male sex was partially accounted for by other factors (aOR 1.41, 95\% CI $0.86-2.33, P=0.17)$.

$B R A F$ V600K mutant tumours, compared to V600E tumours, had an increased odds of being thick tumours than thin tumours (OR 2.39, 95\% CI 1.27-4.50, $P=0.007$ ) and having a high mitotic rate $\left(\mathrm{OR} \geqslant 10 / \mathrm{mm}^{2}\right.$ compared to $<5 / \mathrm{mm}^{2} 2.0595 \%$ CI $1.19-3.54$, $P=0.01)$. The relationship between $\mathrm{V} 600 \mathrm{~K}$ mutation and greater tumour thickness (aOR thick compared to thin tumours 1.69, 95\% CI $0.74-3.84, P=0.2)$ and mitotic rate $\left(\mathrm{aOR} \geqslant 10 / \mathrm{mm}^{2}\right.$ compared to $<5 / \mathrm{mm}^{2} \quad 1.4195 \%$ CI $\left.0.71-2.80, P=0.3\right)$ were partially explained by other factors. There was no evidence to suggest that ulceration was related to BRAF V600 subtype (univariate OR V600K 1.18, 95\% CI 0.75-1.86, $P=0.5$ ).

Sentinel lymph node and tumour mutation status. Among the 690 patients who were eligible for sentinel lymph node biopsy (SLNB), 426 (62\%) underwent this procedure and 119 (28\%) were positive for metastatic melanoma. Among patients with a positive SLNB, $62 \%$ were BRAF mutant. After adjusting for age, sex, mitotic rate, ulceration, Breslow thickness, histologic subtype and anatomical site of primary tumour, $B R A F$ mutant tumours had 1.55 times increased odds (aOR 1.55, 95\% CI 1.14-2.10, $P=0.005$ ) of having a positive SLNB compared to BRAF/NRAS wild-type tumours. There were similar odds of SLNB positivity between NRAS mutant and BRAF/NRAS wild-type tumours (aOR 1.06, 95\% CI $0.73-1.56, P=0.8$ ). 
Table 2. RRR describing clinical and pathological correlates of BRAF mutation estimated in univariate and multivariate multinomial regression analyses

\begin{tabular}{|c|c|c|c|c|c|c|c|c|c|c|c|c|}
\hline \multirow[b]{3}{*}{ Clinicopathological variable } & \multicolumn{6}{|c|}{ BRAF mutant vs BRAF/NRAS wild-type ${ }^{a}$} & \multicolumn{6}{|c|}{ BRAF mutant vs NRAS mutant ${ }^{\mathrm{b}}$} \\
\hline & \multicolumn{3}{|c|}{ Univariate analysis } & \multicolumn{3}{|c|}{ Multivariate analysis } & \multicolumn{3}{|c|}{ Univariate analysis } & \multicolumn{3}{|c|}{ Multivariate analysis } \\
\hline & RRR & $95 \% \mathrm{Cl}$ & $P$-value & RRR & $95 \% \mathrm{Cl}$ & $P$-value & RRR & $95 \% \mathrm{Cl}$ & $P$-value & RRR & $95 \% \mathrm{Cl}$ & $P$-value \\
\hline \multicolumn{13}{|l|}{ Patient sex } \\
\hline Male & 1.00 & & & 1.00 & & & 1.00 & & & 1.00 & & \\
\hline Female & 1.45 & $1.09-1.92$ & 0.01 & 1.21 & $0.88-1.67$ & 0.24 & 1.21 & $0.87-1.69$ & 0.3 & 1.30 & $0.89-1.91$ & 0.18 \\
\hline \multicolumn{13}{|l|}{ Patient age } \\
\hline$<50$ years & 1.00 & & & 1.00 & & & 1.00 & & & 1.00 & & \\
\hline$\geqslant 50$ years & 0.40 & $0.30-0.55$ & $<0.001$ & 0.48 & $0.34-0.67$ & $<0.001$ & 0.28 & $0.18-0.42$ & $<0.001$ & 0.29 & $0.19-0.45$ & $<0.001$ \\
\hline \multicolumn{13}{|l|}{ Anatomical location } \\
\hline Head \& neck & 1.00 & & & 1.00 & & & 1.00 & & & 1.00 & & \\
\hline Trunk & 2.39 & $1.65-3.47$ & $<0.001$ & 2.14 & $1.41-3.24$ & $<0.001$ & 0.92 & $0.54-1.55$ & 0.8 & 0.77 & $0.43-1.36$ & 0.4 \\
\hline Upper extremity & 1.16 & $0.78-1.73$ & 0.5 & 1.06 & $0.68-1.66$ & 0.8 & 0.42 & $0.24-0.72$ & 0.002 & 0.38 & $0.21-0.69$ & 0.002 \\
\hline Lower extremity & 2.11 & $1.37-3.26$ & 0.001 & 1.66 & $1.02-2.71$ & 0.04 & 0.56 & $0.32-0.98$ & 0.04 & 0.41 & $0.22-0.77$ & 0.005 \\
\hline \multicolumn{13}{|l|}{ Breslow thickness } \\
\hline$<1.0 \mathrm{~mm}$ & 1.00 & & & 1.00 & & & 1.00 & & & 1.00 & & \\
\hline $1.00-2.0 \mathrm{~mm}$ & 1.66 & $1.15-2.40$ & 0.007 & 1.69 & $1.12-2.53$ & 0.011 & 0.42 & $0.27-0.67$ & $<0.001$ & 0.36 & $0.22-0.59$ & $<0.001$ \\
\hline $2.01-4.0 \mathrm{~mm}$ & 1.02 & $0.71-1.47$ & 0.9 & 1.23 & $0.80-1.88$ & 0.3 & 0.39 & $0.24-0.62$ & $<0.001$ & 0.39 & $0.23-0.66$ & $<0.001$ \\
\hline$>4.0 \mathrm{~mm}$ & 1.03 & $0.68-1.56$ & 0.9 & 1.39 & $0.83-2.35$ & 0.22 & 0.59 & $0.34-1.05$ & 0.07 & 0.58 & $0.31-1.13$ & 0.11 \\
\hline \multicolumn{13}{|l|}{ Histologic subtype } \\
\hline SSM & 1.00 & & & 1.00 & & & 1.00 & & & 1.00 & & \\
\hline NM & 0.78 & $0.56-1.07$ & 0.13 & 0.88 & $0.60-1.31$ & 0.5 & 0.82 & $0.56-1.19$ & 0.3 & 1.15 & $0.75-1.78$ & 0.5 \\
\hline LMM & 0.19 & $0.10-0.35$ & $<0.001$ & 0.33 & $0.17-0.65$ & 0.001 & 1.01 & $0.36-2.87$ & 1.0 & 1.18 & $0.40-3.49$ & 0.8 \\
\hline \multicolumn{13}{|l|}{ Mitotic rate $\left(\mathrm{n} / \mathrm{mm}^{2}\right)$} \\
\hline$<5$ & 1.00 & & & & & & 1.00 & & & & & \\
\hline $5-9$ & 1.15 & $0.79-1.67$ & 0.5 & & & & 0.73 & $0.48-1.10$ & 0.13 & & & \\
\hline$\geqslant 10$ & 1.03 & $0.70-1.52$ & 0.9 & & & & 0.87 & $0.55-1.38$ & 0.6 & & & \\
\hline \multicolumn{13}{|l|}{ Ulceration } \\
\hline No & 1.00 & & & & & & 1.00 & & & & & \\
\hline Yes & 1.20 & $0.88-1.64$ & 0.3 & & & & 0.92 & $0.64-1.32$ & 0.7 & & & \\
\hline \multicolumn{13}{|c|}{ 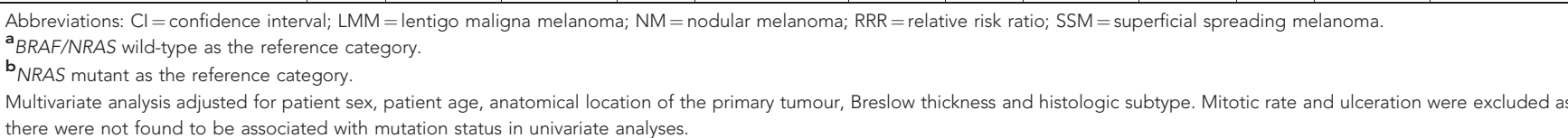 } \\
\hline
\end{tabular}

Site of first detected metastasis. Over a median 4.7 year followup period (IQR 3.6-5.9 years), 306 (29\%) patients developed metastasis. Of these, 73 (24\%), 192 (63\%) and 41 (13\%) patients developed distant, regional lymph node and satellite/in-transit metastasis as the first site of metastasis, respectively. Among the 192 patients who developed lymph node metastasis as the site of first metastasis, 119 (62\%) were detected by a positive SLNB and the remainder were detected either clinically or radiologically. Excluding lymph node metastases detected by a tumour-positive SLNB, the mode of detection for first metastasis was radiological in $47 \%$ and clinical in 53\%. The mode of detection was more commonly radiological than clinical for distant metastases $(78 \% v s$ $22 \%$, respectively) and vice versa for satellite/in-transit metastases (15\% vs $85 \%$, respectively).

Clinicopathological characteristics associated with the site of first metastasis. Table 3 displays the site of first metastasis by various patient- and tumour-related characteristics. In the multivariate regression model, patients with tumours located on the head and neck region had a 2.80 times increased risk compared to patients with truncal tumours of developing satellite/in-transit metastasis rather than lymph node metastasis (RRR 2.80, 95\% CI 1.04-7.52, $P=0.04$ ). In multivariate analysis, there was weak evidence to suggest that females were more likely than males to develop satellite/in-transit metastasis rather than distant metastasis as first metastasis (RRR 2.09, 95\% CI 0.88-4.98, $P=0.1$ ).
Tumour mutation status and the site of first detected metastasis. The site of first metastasis was similar in both NRAS mutant and BRAF/NRAS wild-type mutant groups (Table 4). BRAF mutant tumours, compared to BRAF/NRAS wild-type tumours, had increased risk of developing regional lymph node metastasis rather than satellite/in-transit metastasis as first metastasis (univariate RRR 3.24, 95\% CI 1.49-7.08, $P=0.003$ ), This increased risk remained statistically significant after adjustments (RRR 2.46 95\% CI 1.07-5.69, $P=0.04$; Table 4). BRAF mutant tumours had increased risk of developing regional lymph node metastasis rather than distant metastasis as the site of first metastasis; however, this increased risk was not statistically significant (RRR 1.32, 95\% CI $0.70-2.49, P=0.4)$.

Metastatic pathways and mortality in patients with primary cutaneous melanoma. Among the 306 patients who developed metastasis, 174 developed distant metastatic disease. The proportions of patients who followed each of the four distinct metastatic pathways are displayed in Figure 1.

During the study period, 134 patients died. Of these, 103 died from metastatic melanoma, 3 from another malignancy, 10 from other causes and 18 from unknown causes. Of the 103 patients who died from metastatic melanoma, $24.3 \%$ of tumours had an NRAS mutation, $59.2 \%$ had a BRAF mutation and $16.5 \%$ had BRAF/ NRAS wild-type tumours.

In univariate analysis, both patients with $B R A F$ mutant and NRAS mutant melanomas had a worse MSS than patients with 
$B R A F / N R A S$ wild-type tumours (hazard ratio (HR) 2.46 95\% CI $1.43-4.20, P=0.001$; HR 2.70, 95\% CI 1.46-5.00, $P=0.002$, respectively). When adjusted for age, sex, ulceration, Breslow thickness, histologic subtype and mitotic rate, the relationship between BRAF mutation and MSS was slightly strengthened (HR 2.95, 95\% CI 1.64-5.29, $P<0.001)$. After adjustments, patients with NRAS mutant melanomas had a worse MSS than patients with $B R A F / N R A S$ wild-type melanomas (HR 3.08, 95\% CI 1.56-6.08, $P=0.001)$.

Clinicopathological and molecular characteristics and the anatomical metastatic pathways. There was little evidence to suggest that the pathways of progression to distant disease differed by mutation status. Similarly, patient age and sex, ulceration, Breslow thickness, mitotic rate, histologic subtype and tumour

Table 3. Patient- and tumour-related characteristics and the site of first tumour metastasis

\begin{tabular}{|c|c|c|c|c|}
\hline \multirow[b]{2}{*}{$\begin{array}{l}\text { Patient and } \\
\text { tumour-related } \\
\text { characteristics }\end{array}$} & \multicolumn{4}{|c|}{ Site of first tumour metastasis (\%) } \\
\hline & $\begin{array}{c}\text { Distant } \\
\text { metastasis }\end{array}$ & $\begin{array}{c}\text { Lymph } \\
\text { node } \\
\text { metastasis }\end{array}$ & $\begin{array}{c}\text { Satellite/ } \\
\text { in-transit } \\
\text { metastasis }\end{array}$ & $P$-value \\
\hline \multicolumn{5}{|l|}{ Patient sex } \\
\hline $\begin{array}{l}\text { Males } \\
\text { Females }\end{array}$ & $\begin{array}{l}52(25.9) \\
21(20.0)\end{array}$ & $\begin{array}{r}126(62.7) \\
66(62.9)\end{array}$ & $\begin{array}{l}23(11.4) \\
18(17.1)\end{array}$ & 0.3 \\
\hline \multicolumn{5}{|l|}{ Patient age } \\
\hline $\begin{array}{l}<50 \text { years } \\
\geqslant 50 \text { years }\end{array}$ & $\begin{array}{l}16(19.8) \\
56(25.0) \\
\end{array}$ & $\begin{array}{r}59(72.8) \\
133(59.4) \\
\end{array}$ & $\begin{array}{c}6(7.4) \\
35(15.6)\end{array}$ & 0.07 \\
\hline \multicolumn{5}{|c|}{ Anatomical location } \\
\hline $\begin{array}{l}\text { Head \& neck } \\
\text { Trunk } \\
\text { Upper extremity } \\
\text { Lower extremity }\end{array}$ & $\begin{array}{r}27(32.5) \\
25(22.7) \\
7(14.3) \\
12(20.3)\end{array}$ & $\begin{array}{l}42(50.6) \\
77(70.0) \\
32(65.3) \\
38(64.4)\end{array}$ & $\begin{array}{c}14(16.9) \\
8(7.3) \\
10(20.4) \\
9(15.3)\end{array}$ & 0.04 \\
\hline \multicolumn{5}{|c|}{ Breslow thickness } \\
\hline $\begin{array}{l}<1.0 \mathrm{~mm} \\
1.0-2.0 \mathrm{~mm} \\
2.01-4.0 \mathrm{~mm} \\
>4.0 \mathrm{~mm}\end{array}$ & $\begin{array}{r}7(22.6) \\
20(24.4) \\
24(21.6) \\
20(25.6)\end{array}$ & $\begin{array}{l}18(58.1) \\
56(68.3) \\
71(64.0) \\
45(57.7)\end{array}$ & $\begin{array}{c}3(19.4) \\
6(7.3) \\
16(14.4) \\
13(16.7)\end{array}$ & 0.6 \\
\hline \multicolumn{5}{|c|}{ Histologic subtype } \\
\hline $\begin{array}{l}\text { SSM } \\
\text { NM } \\
\text { LMM }\end{array}$ & $\begin{array}{r}36(21.8) \\
26(23.9) \\
6(40.0)\end{array}$ & $\begin{array}{r}110(66.7) \\
65(59.6) \\
5(33.3)\end{array}$ & $\begin{array}{r}19(11.5) \\
18(16.5) \\
4(26.7)\end{array}$ & 0.11 \\
\hline \multicolumn{5}{|c|}{ Mitotic rate $\left(\mathrm{n} / \mathrm{mm}^{2}\right)$} \\
\hline $\begin{array}{l}<5 \\
5-9 \\
>10\end{array}$ & $\begin{array}{l}31(21.7) \\
17(22.7) \\
23(28.1)\end{array}$ & $\begin{array}{l}91(63.4) \\
51(68.0) \\
47(57.3)\end{array}$ & $\begin{aligned} 21 & (14.7) \\
7 & (9.3) \\
12 & (14.6)\end{aligned}$ & 0.6 \\
\hline \multicolumn{5}{|l|}{ Ulceration } \\
\hline $\begin{array}{l}\text { Yes } \\
\text { No }\end{array}$ & $\begin{array}{l}36(21.4) \\
32(24.8)\end{array}$ & $\begin{array}{r}108(64.3) \\
80(62.0)\end{array}$ & $\begin{array}{l}24(14.3) \\
17(13.2)\end{array}$ & 0.8 \\
\hline
\end{tabular}

location were not associated with the four metastatic pathways (Supplementary analyses).

Tumour mutation status and the patterns of organ involvement. With respect to patients who developed central nervous system (CNS) metastasis, 50/77 (65\%) had a BRAF mutant tumour and $17 / 77$ (22\%) had a NRAS mutant tumour. BRAF mutation and NRAS mutation were associated with increased odds of developing CNS metastasis compared to BRAF/NRAS wild-type tumours (BRAF aOR 4.65, 95\% CI 2.23-9.69, $P<0.001$; NRAS aOR 4.03, 95\% CI $1.72-9.44, P=0.001)$.

Among patients who developed liver metastasis, 40/65 (62\%) had a BRAF mutant tumour and 14/65 (21\%) had an NRAS mutant tumour. There was evidence to suggest that the presence of either a $B R A F$ or NRAS mutation was associated with an increased odds of developing liver metastasis compared to $B R A F / N R A S$ wild-type tumours (BRAF aOR 3.09, 95\% CI 1.49-6.42, $P=0.003$; NRAS aOR 3.17, 95\% CI 1.32-7.58, $P=0.01)$. Among patients who developed lung metastasis, 50/98 (51\%) had a BRAF mutant tumour and 23/98 (24\%) had a NRAS mutant tumour. While there was evidence to suggest that NRAS mutation was associated with lung metastasis (aOR 2.44, 95\% CI 1.21-4.93, $P=0.013$ ), there was uncertainty regarding an association between $B R A F$ mutation and the development of lung metastasis (aOR 1.78, 95\% CI $0.98-3.25$ $P=0.06)$.

Time course to the development of detected first metastasis. The median time to satellite/in-transit, regional lymph node (excluding patients with a tumour-positive SLNB) and distant metastasis as the site of first detected metastasis was 17.0 months (IQR 5.3-30.3 months), 16.1 months (IQR 7.1-27.7 months) and 14.9 months (IQR 6.5-26.9 months), respectively $(P=0.09)$. Excluding patients with a tumour-positive SLNB, the overall median time to first metastasis was 14.7 months (IQR 5.9-25.4 months). Excluding patients with a tumour-positive SLNB, the median time to first metastasis was shorter in patients with $B R A F$ mutant tumours (12.5 months, IQR 5.0-22.5 months) compared to NRAS mutant (13.4 months, IQR 5.6-21.7) and BRAF/NRAS wildtype tumours (18.1 months, IQR 7.4-32.3 months) $(P=0.14)$.

Time course to the development of distant metastasis by the different metastatic pathways. The median time to distant metastasis was similar among the four metastatic pathways (Table 5). The median time to distant metastasis was similar among patients with BRAF mutant (15.0 months (IQR 8.5-26.4)) NRAS mutant (16.2 months (IQR 10.8-25.1)) and BRAF/NRAS wild-type (17.2 months [IQR 11.5-29.2]) tumours $(P=0.7)$.

\section{DISCUSSION}

Of the 1048 patients included in our analysis, 306 (29\%) developed metastasis during the study period and among these, $24 \%, 63 \%$ and

Table 4. Univariate and multivariate multinomial regression analyses of tumour mutation status and the site of first metastasis

\begin{tabular}{|c|c|c|c|c|c|c|c|c|c|c|c|c|c|c|}
\hline \multirow[b]{2}{*}{ Mutation status } & \multicolumn{6}{|c|}{ Site of first metastasis } & \multicolumn{4}{|c|}{ Univariate analysis } & \multicolumn{4}{|c|}{ Multivariate analysis $^{a}$} \\
\hline & $n$ & $\%$ & $n$ & $\%$ & $n$ & $\%$ & RRR $(95 \% \mathrm{Cl})$ & $P$-value & RRR $(95 \% \mathrm{Cl})$ & $P$-value & RRR $(95 \% \mathrm{Cl})$ & $P$-value & RR $(95 \% \mathrm{Cl})$ & $P$-value \\
\hline NRAS mutant & 9 & 16 & 37 & 64 & 12 & 21 & $1.68(0.68-4.19)$ & 0.3 & $1.14(0.39-3.33)$ & 0.8 & $1.39(0.52-3.72)$ & 0.5 & $1.28(0.41-4.03)$ & 0.7 \\
\hline BRAF/NRAS WT & 18 & 22 & 44 & 53 & 21 & 25 & 1.00 & & 1.00 & & 1.00 & & 1.00 & \\
\hline
\end{tabular}




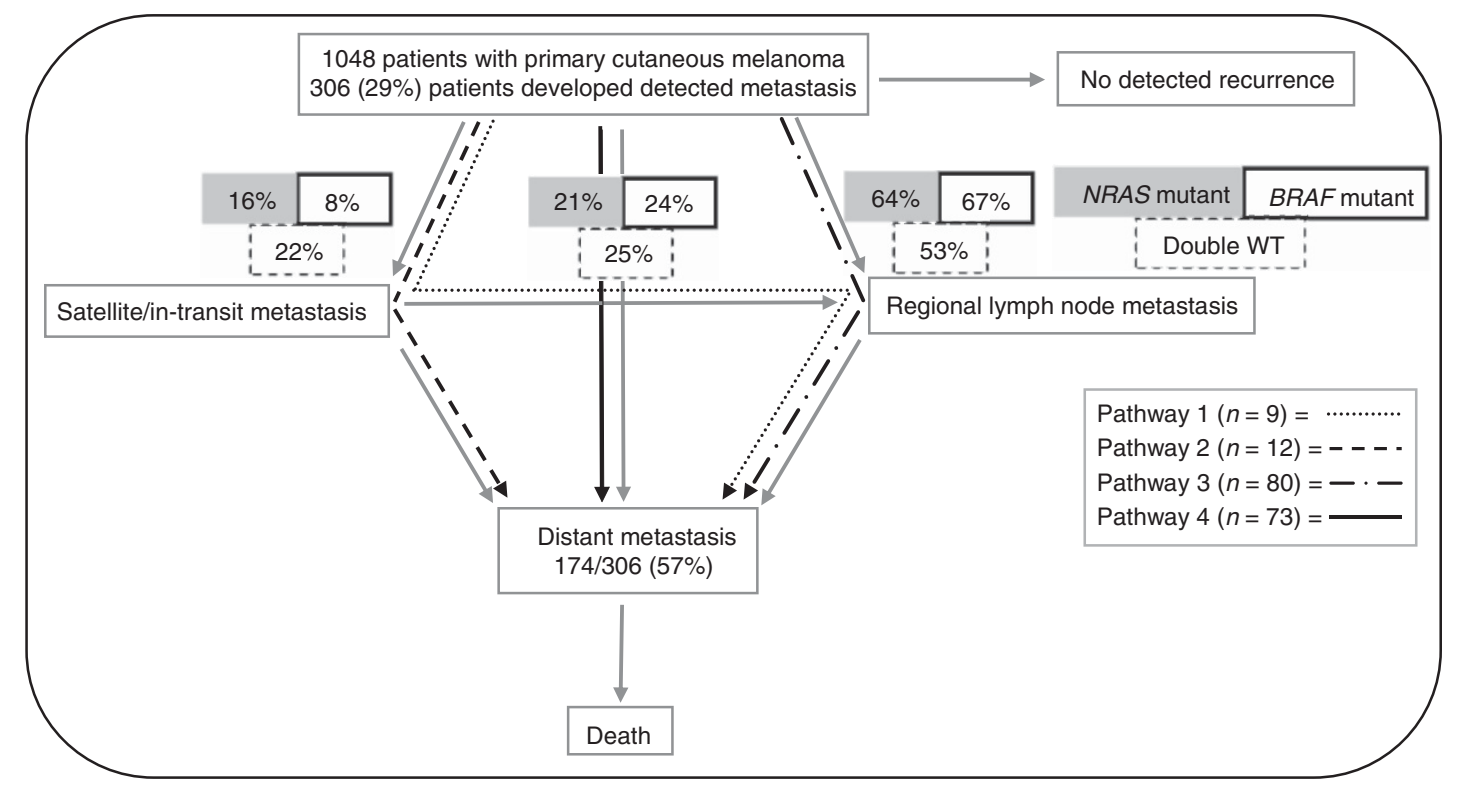

Figure 1. Metastatic pathways in patients with primary cutaneous melanoma. Figure adapted from Meier et al (2002). The metastatic pathways of progression: 1-development of satellite or in-transit metastases followed by regional lymph node metastases and distant metastases, 2development of satellite or in-transit metastases followed by distant metastases, 3-development of regional lymph node metastases followed by distant metastases and 4-development of distant metastases as first tumour recurrence.

Table 5. Time to distant metastasis in patients with primary cutaneous melanoma by four different metastatic pathways

\begin{tabular}{|l|c|c|c|}
\hline $\begin{array}{l}\text { Metastatic } \\
\text { pathway }\end{array}$ & $\begin{array}{c}\text { Median time } \\
\text { to distant } \\
\text { metastasis } \\
\text { (months) }\end{array}$ & $\begin{array}{c}\text { IQR } \\
\text { (months) }\end{array}$ & $P$-value \\
\hline $\begin{array}{l}\text { Pathway 1 } \\
\text { Development of satellite or in-transit } \\
\text { metastases followed by regional } \\
\text { lymph node metastases and distant } \\
\text { metastases }\end{array}$ & 15 & $(9,17)$ & 0.4 \\
\hline $\begin{array}{l}\text { Pathway 2 } \\
\text { Development of satellite or in-transit } \\
\text { metastases followed by distant } \\
\text { metastases }\end{array}$ & 16 & $(7,26)$ & - \\
\hline $\begin{array}{l}\text { Pathway 3 } \\
\text { Development of regional lymph } \\
\text { node metastases followed by } \\
\text { distant metastases }\end{array}$ & 18 & $(10,27)$ & - \\
\hline $\begin{array}{l}\text { Pathway 4 } \\
\text { Development of distant metastases } \\
\text { as first tumour recurrence }\end{array}$ & 15 & $(7,28)$ & - \\
\hline Total & 16 & $(9,26)$ & - \\
\hline Abbreviation: IQR =interquartile range. & & & \\
\hline
\end{tabular}

13\% developed distant, regional lymph node and satellite/in-transit metastasis as the site of first metastasis, respectively. These findings are consistent with the limited available literature, which suggests that $15-35 \%$ of patients with primary cutaneous melanoma exhibit disease progression and of these patients, approximately two-thirds initially present with loco-regional disease and one-third present with distant metastasis (Reintgen et al, 1992; Soong et al, 1998; Cohn-Cedermark et al, 1999; Meier et al, 2002; Tejera-Vaquerizo et al, 2007).

Meier et al's (2002) landmark study traced the metastatic pathways of 3001 patients with primary cutaneous melanoma from 1976 to 1996. Among these patients, 466 developed recurrence and of these, $28 \%, 50 \%$ and $22 \%$ developed distant, lymph node and satellite/in-transit metastasis as the site of primary recurrence (Meier et al, 2002). In our cohort, the proportion of patients who developed regional lymph metastasis as the site of first metastasis was higher than previously described, likely due to the increased use of SLNB in a substantial fraction of patients at the institutions included in our study. The use of SLNB was not routine at the time of Meier et al's study (Meier et al, 2002) or at the time of other previous studies investigating the metastatic pathways of patients with cutaneous melanoma (Reintgen et al, 1992; Soong et al, 1998; Cohn-Cedermark et al, 1999; Tejera-Vaquerizo et al, 2007).

Consistent with the existing literature (Maldonado et al, 2003; Lang \& MacKie, 2005; Edlundh-Rose et al, 2006; Poynter et al, 2006; Liu et al, 2007; Thomas et al, 2007; Viros et al, 2008; Broekaert et al, 2010; Hacker et al, 2010; Bauer et al, 2011; Devitt et al, 2011; Lee et al, 2011; Long et al, 2011; Menzies et al, 2012; Ekedahl et al, 2013; Barbour et al, 2014; Carlino et al, 2014; Kim et al, 2015; Thomas et al, 2015), our study found that BRAF positivity is associated with younger age and superficial spreading subtype. In the multivariate regression analysis, $B R A F$ mutation was not associated with Breslow thickness. Previous work on a subset of this cohort suggested that BRAF mutant tumours were thinner at diagnosis compared to BRAF wild-type tumours (Mar et al, 2014). However, other studies have found no relationship between Breslow thickness and BRAF mutation (Shinozaki et al, 2004; Edlundh-Rose et al, 2006; Bauer et al, 2011; Lee et al, 2011; Long et al, 2011; Bucheit et al, 2013; Carlino et al, 2014).

Among BRAF mutant tumours, the frequency (24\%) of BRAF $\mathrm{V} 600 \mathrm{~K}$ in our cohort was somewhat higher than expected. The frequency of $B R A F \mathrm{~V} 600 \mathrm{~K}$ mutation has been reported to range between 6 and 30\% (Willmore-Payne et al, 2005; Spittle et al, 2007; Ugurel et al, 2007; Halaban et al, 2010; Rubinstein et al, 2010; Long et al, 2011; Jewell et al, 2012; Lovly et al, 2012; Menzies et al, 2012; Bucheit et al, 2013; Greaves et al, 2013; Heinzerling et al, 2013). Of note, Long et al's Australian study determined that $20 \%$ of tumours had BRAF V600K oncogenic mutations (Long et al, 2011). The broad range for the reported $\mathrm{V} 600 \mathrm{~K}$ frequency may be explained by differences in methods used for mutation analysis. For instance, 
studies using methods with lower sensitivities for reliably detecting non-V600E mutations (such as Sanger sequencing) or with lower specificities in distinguishing variant mutations may underestimate the frequency of mutations in V600K (Long et al, 2011; Anderson et al, 2012; Halait et al, 2012; Heinzerling et al, 2013). Moreover, mutations in $\mathrm{V} 600 \mathrm{~K}$ may be more frequent in Australian populations due to high ultraviolet exposure given the higher proportion of melanomas arising in chronic sun-damaged skin (Menzies et al, 2012; Voskoboynik et al, 2016).

In our study, compared to patients with BRAF V600E mutant tumours, patients with $B R A F \mathrm{~V} 600 \mathrm{~K}$ mutant tumours were more likely to be older and have tumours located on the head and neck region. Previous studies have similarly demonstrated associations between V600K genotype with older patient age and head and neck location (Jewell et al, 2012; Menzies et al, 2012; Bucheit et al, 2013). These findings suggest that different genotypes exist within $B R A F$ mutant melanoma, whereby V600K and V600E genotypes may represent biologically and clinically distinct entities.

In our study, NRAS positivity was more common in older patients and in tumour located on the extremities compared to the head and necsk region. Several other studies have demonstrated an association between NRAS mutation and older patient age (Goel et al, 2006; Devitt et al, 2011; Ekedahl et al, 2013); however, a metaanalysis did not demonstrate this association (Lee et al, 2011). Other studies have similarly revealed that NRAS mutant melanomas have a propensity to develop on the extremities compared to the head and neck region (Edlundh-Rose et al, 2006; Ellerhorst et al, 2011; Jakob et al, 2012). Thomas et al's cohort study demonstrated an inverse relationship between NRAS mutant melanomas and scalp/neck location (Thomas et al, 2015).

Furthermore, even when adjusted for other factors, $B R A F$ mutant tumours had an increased risk of regional lymph node metastasis compared to satellite/in-transit metastasis as the site of first metastasis. Our study has also demonstrated that patients with melanomas harbouring a BRAF mutation had increased odds of a tumour-positive SLNB. The fact that BRAF mutation was associated on multivariate analysis with nodal disease, whether detected clinically or by a tumour-positive SLNB, suggests that this is likely to be a true association. We have previously reported an association between $B R A F$ mutation status and nodal involvement at diagnosis in a subset of the MMP cohort (Mar et al, 2014). Broekaert et al (2010) suggested that BRAF mutant tumours metastasise more frequently to regional lymph nodes, with $B R A F$ wild-type tumours more likely to metastasise to non-nodal sites. In contrast, another study found that BRAF mutant melanomas were most likely to recur with distant metastasis as the site of first recurrence and that isolated regional lymph node metastasis was rare (Barbour et al, 2014).

Several studies that have investigated the relationship between mutation status and the patterns of visceral involvement in metastatic disease (Chang et al, 2004; Jakob et al, 2012; Carlino et al, 2014; Maxwell et al, 2016). Our study indicated that BRAF mutation and NRAS mutation were associated with the subsequent development of CNS metastasis (aOR 4.65, 95\% CI 2.23-9.69 $P<0.001$; aOR 4.03, 95\% CI 1.72-9.44, $P=0.001$, respectively) and liver metastasis (aOR 3.09, 95\% CI 1.49-6.42 $P=0.003$; aOR 3.17, 95\% CI 1.32-7.58, $P=0.01$, respectively). Compared to BRAF/ NRAS wild-type tumours, NRAS mutation was also associated with lung metastasis (aOR 2.44, 95\% CI 1.21-4.93, $P=0.013$ ). These wide CIs indicate some uncertainty in our findings and further prospective studies are required to validate our results. Consistent with our finding of an association between liver metastasis and $B R A F$ mutation, a small retrospective study found that melanomas harbouring $B R A F$ mutations were more likely than $B R A F$ wild-type tumours to metastasise to the liver (Chang et al, 2004). In contrast, Jakob et al (2012) retrospective cohort study concluded that there was no association between mutation status and liver metastasis.
Jakob et al (2012) study revealed that tumour mutation was associated with an increased risk of CNS involvement at diagnosis of stage IV disease $(P=0.008)$, with melanomas harbouring $B R A F$ and NRAS mutations more likely to have CNS involvement compared to BRAF/NRAS wild-type patients $(24.1 \%, 23.1 \%$ and $12.4 \%$, respectively). Carlino et al's more recent study demonstrated a trend towards higher rates of brain metastasis at initial stage IV diagnosis, in keeping with Jakob and colleagues' study (Jakob et al, 2012); however, the risk of brain metastasis at any time was comparable irrespective of $B R A F / N R A S$ mutation status (Carlino et al, 2014). A recent, single-institution, retrospective cohort study demonstrated that BRAF-V600 patients, who were not treated with a selective BRAF inhibitor, compared to $B R A F$ wild-type patients, had an increased risk of brain metastasis $(P=0.027$; Maxwell et al, 2016).

In our study, patients with tumours located on the head and neck region had an increased risk of developing satellite/in-transit metastasis compared to nodal metastasis. In accordance with this finding, in Meier et al's study, satellite or in-transit metastases were more likely to occur in patients with tumours located on the head and neck $(P<0.001$; Meier et al, 2002).

In our study, Breslow thickness was not related to the site of first metastasis. Consistent with this, Cohn-Cedermark and colleagues' study demonstrated that the type of primary recurrence was unrelated to the Breslow thickness of the primary tumour (CohnCedermark et al, 1999). Contrary to their findings and ours, in Meier et al's study, tumours between 0.75 and $1.5 \mathrm{~mm}$ in thickness demonstrated the highest frequency of direct distant metastases, while tumours $<0.76 \mathrm{~mm}$ and $>1.5 \mathrm{~mm}$ in thickness had increased rates of satellite or in-transit metastasis (Meier et al, 2002). These findings have not been validated elsewhere and we are unable to provide a meaningful explanation for their results. Tejera-Vaquerizo and colleagues' study reported that melanomas greater than $4 \mathrm{~mm}$ in thickness had an increased risk of developing distant metastasis compared to locoregional metastasis as the first site of recurrence (Tejera-Vaquerizo et al, 2007). In view of their small sample size, it is difficult to draw any firm conclusions.

Excluding patients with positive SLNB, the median time course to the first detected metastasis was similar among those who developed satellite/in-transit, regional lymph node and distant metastasis $(P=0.14)$. In Meier and colleagues' study, the median time to first tumour recurrence as distant, lymph node and satellite/in-transit metastasis was 25 months, 16 months and 17 months, respectively (Meier et al, 2002). Excluding patients with a tumour-positive SLNB, the decreased median time to first detected metastasis (15 months) in our study is likely due to referral bias as our patient cohort may have had more aggressive disease due to the fact that our study was conducted at three major tertiary referral centres and the increasing use of radiological surveillance in high-risk patients. Indeed, among patients with distant metastasis as the site of first metastasis, the mode of detection was radiological in $78 \%$ of patients. At the time of Meier et al's study, routine radiological surveillance of high-risk patients was likely not performed (Meier et al, 2002). Furthermore, it is important to consider lead time bias in the time course to the development of metastases. That is, small in-transit and lymph node metastases are more likely to be detected clinically, leading to earlier detection, compared to distant visceral metastases of the same size, which may be asymptomatic.

In our study, the time course to the development of distant metastatic disease was established to be independent of the anatomical metastatic pathway. Other studies have similarly demonstrated that the time to distant metastasis is similar across the various metastatic pathways, irrespective of the site of first metastasis (Dong et al, 2000; Meier et al, 2002; Tejera-Vaquerizo et al, 2007). 
The median time to the development of distant metastatic disease in patients with $B R A F$ mutant tumours was shorter than in patients with BRAF/NRAS wild-type tumours; however, this difference was not statistically significant. Other studies have also failed to demonstrate a significant difference in the time to distant metastatic disease according to mutation status (Chang et al, 2004; Long et al, 2011; Carlino et al, 2014).

Strengths of our study included the large sample size and the multicentre and prospective nature of the study design. In addition, the MMP database includes comprehensive information on disease recurrence and high-quality longitudinal follow-up data, which compares favourably to other databases. It also contains a rich data set of phenotypic and tumour-related variables, including mutational data. Therefore, the MMP database provided a clinically, histologically and molecularly well-characterised cohort of patients.

Nonetheless, referral bias discussed above is a limitation of our study. Furthermore, many of the new systemic agents used in melanoma treatment may alter the natural course of the disease (Hodi et al, 2010; Flaherty et al, 2012; Hauschild et al, 2012); therefore, the relationship between disease progression and mutation status may be potentially confounded by these therapeutic agents. Another limitation of our study is that the median follow-up time was 4.7 years; thus, our study would not have captured patients with slow tempo disease. However, in view of the fact that the IQR for the time to distant metastatic disease among all the metastatic pathways was between 9 and 26 months, our study likely captured the vast majority of recurrences and therefore, our median follow-up period is considered to be reasonable. When our findings are interpreted within this context, our results provide information on the clinical, pathological and mutational characteristics related to the routes of metastasis in a large Australian cohort. Nonetheless, further studies with a comparatively longer observational period are warranted in order to definitively capture patients with slow tempo disease.

To conclude, patients with BRAF mutant tumours have an increased risk of regional lymph node metastasis as the site of first metastasis and sentinel lymph node positivity. The presence of either a BRAF or NRAS mutation was associated with the development of CNS and liver metastasis and the presence of an NRAS mutation was associated with the development of lung metastasis. If these findings are validated in additional prospective studies, a role for heightened visceral organ surveillance may be warranted in patients with tumours harbouring these somatic mutations.

\section{ACKNOWLEDGEMENTS}

We would like to thank Ms Sonia Louise Mailer for her work as the MMP database manager. NRA is supported by the Australian Postgraduate Award; this research project was supported by the Victorian Government through the Victorian Cancer Agency Translational Research Program; GAM is supported by the NHMRC and The Lorenzo Galli Chair in melanoma and Skin Cancer from the University of Melbourne.

\section{CONFLICT OF INTEREST}

The authors declare no conflict of interest.

\section{REFERENCES}

Anderson S, Bloom KJ, Vallera DU, Rueschoff J, Meldrum C, Schilling R, Kovach B, Lee JR, Ochoa P, Langland R, Halait H, Lawrence HJ,
Dugan MC (2012) Multisite analytic performance studies of a real-time polymerase chain reaction assay for the detection of BRAF V600E mutations in formalin-fixed, paraffin-embedded tissue specimens of malignant melanoma. Arch Pathol Lab Med 136: 1385-1391.

Barbour AP, Tang YH, Armour N, Dutton-Regester K, Krause L, Loffler KA, Lambie D, Burmeister B, Thomas J, Smithers BM, Hayward NK (2014) BRAF mutation status is an independent prognostic factor for resected stage IIIB and IIIC melanoma: implications for melanoma staging and adjuvant therapy. Eur J Cancer 50: 2668-2676.

Bauer J, Buttner P, Murali R, Okamoto I, Kolaitis NA, Landi MT, Scolyer RA, Bastian BC (2011) BRAF mutations in cutaneous melanoma are independently associated with age, anatomic site of the primary tumor, and the degree of solar elastosis at the primary tumor site. Pigment Cell Melanoma Res 24: 345-351.

Broekaert SMC, Roy R, Okamoto I, van den Oord J, Bauer J, Garbe C, Barnhill RL, Busam KJ, Cochran AJ, Cook MG, Elder DE, McCarthy SW, Mihm MC, Schadendorf D, Scolyer RA, Spatz A, Bastian BC (2010) Genetic and morphologic features for melanoma classification. Pigment Cell Melanoma Res 23: 763-770.

Bucheit AD, Syklawer E, Jakob JA, Bassett Jr RL, Curry JL, Gershenwald JE, Kim KB, Hwu P, Lazar AJ, Davies MA (2013) Clinical characteristics and outcomes with specific BRAF and NRAS mutations in patients with metastatic melanoma. Cancer 119: 3821-3829.

Carlino MS, Haydu LE, Kakavand H, Menzies AM, Hamilton AL, Yu B, Ng CC, Cooper WA, Thompson JF, Kefford RF, O’Toole SA, Scolyer RA, Long GV (2014) Correlation of BRAF and NRAS mutation status with outcome, site of distant metastasis and response to chemotherapy in metastatic melanoma. Br J Cancer 111: 292-299.

Chang DZ, Panageas KS, Osman I, Polsky D, Busam K, Chapman PB (2004) Clinical significance of BRAF mutations in metastatic melanoma. $J$ Transl Med 2: 46.

Cohn-Cedermark G, Mansson-Brahme E, Rutqvist LE, Larsson O, Singnomklao T, Ringborg U (1999) Metastatic patterns, clinical outcome, and malignant phenotype in malignant cutaneous melanoma. Acta Oncol 38: 549-557.

Colombino M, Capone M, Lissia A, Cossu A, Rubino C, De Giorgi V, Massi D, Fonsatti E, Staibano S, Nappi O, Pagani E, Casula M, Manca A, Sini M, Franco R, Botti G, Caraco C, Mozzillo N, Ascierto PA, Palmieri G (2012) BRAF/NRAS mutation frequencies among primary tumors and metastases in patients with melanoma. J Clin Oncol 30: 2522-2529.

Devitt B, Liu W, Salemi R, Wolfe R, Kelly J, Tzen CY, Dobrovic A, McArthur G (2011) Clinical outcome and pathological features associated with NRAS mutation in cutaneous melanoma. Pigment Cell Melanoma Res 24: 666-672.

Dong XD, Tyler D, Johnson JL, DeMatos P, Seigler HF (2000) Analysis of prognosis and disease progression after local recurrence of melanoma. Cancer 88: 1063-1071.

Edlundh-Rose E, Egyhazi S, Omholt K, Mansson-Brahme E, Platz A, Hansson J, Lundeberg J (2006) NRAS and BRAF mutations in melanoma tumours in relation to clinical characteristics: a study based on mutation screening by pyrosequencing. Melanoma Res 16: 471-478.

Ekedahl H, Cirenajwis H, Harbst K, Carneiro A, Nielsen K, Olsson H, Lundgren L, Ingvar C, Jönsson G (2013) The clinical significance of BRAF and NRAS mutations in a clinic-based metastatic melanoma cohort. $\mathrm{Br} J$ Dermatol 169: 1049-1055.

Ellerhorst JA, Greene VR, Ekmekcioglu S, Warneke CL, Johnson MM, Cooke CP, Wang LE, Prieto VG, Gershenwald JE, Wei Q, Grimm EA (2011) Clinical correlates of NRAS and BRAF mutations in primary human melanoma. Clin Cancer Res 17: 229-235.

Flaherty KT, Robert C, Hersey P, Nathan P, Garbe C, Milhem M, Demidov LV, Hassel JC, Rutkowski P, Mohr P, Dummer R, Trefzer U, Larkin JM, Utikal J, Dreno B, Nyakas M, Middleton MR, Becker JC, Casey M, Sherman LJ, Wu FS, Ouellet D, Martin AM, Patel K, Schadendorf D. Group MS (2012) Improved survival with MEK inhibition in BRAF-mutated melanoma. N Engl J Med 367: 107-114.

Goel VK, Lazar AJ, Warneke CL, Redston MS, Haluska FG (2006) Examination of mutations in BRAF, NRAS, and PTEN in primary cutaneous melanoma. J Invest Dermatol 126: 154-160.

Greaves WO, Verma S, Patel KP, Davies MA, Barkoh BA, Galbincea JM, Yao H, Lazar AJ, Aldape KD, Medeiros LJ, Luthra R (2013) Frequency and spectrum of BRAF mutations in a retrospective, single-institution study of 1112 cases of melanoma. J Mol Diagn 15: 220-226.

Hacker E, Hayward NK, Dumenil T, James MR, Whiteman DC (2010) The association between MC1R genotype and BRAF mutation status in 
cutaneous melanoma: findings from an Australian population. J Invest Dermatol 130: 241-248.

Halaban R, Zhang W, Bacchiocchi A, Cheng E, Parisi F, Ariyan S, Krauthammer M, McCusker JP, Kluger Y, Sznol M (2010) PLX4032, a selective BRAF(V600E) kinase inhibitor, activates the ERK pathway and enhances cell migration and proliferation of BRAF melanoma cells. Pigment Cell Melanoma Res 23: 190-200.

Halait H, Demartin K, Shah S, Soviero S, Langland R, Cheng S, Hillman G, Wu L, Lawrence HJ (2012) Analytical performance of a real-time PCR-based assay for V600 mutations in the BRAF gene, used as the companion diagnostic test for the novel BRAF inhibitor vemurafenib in metastatic melanoma. Am J Surg Pathol 21: 1-8.

Hauschild A, Grob JJ, Demidov LV, Jouary T, Gutzmer R, Millward M, Rutkowski P, Blank CU, Miller Jr. WH, Kaempgen E, Martin-Algarra S, Karaszewska B, Mauch C, Chiarion-Sileni V, Martin AM, Swann S, Haney P, Mirakhur B, Guckert ME, Goodman V, Chapman PB (2012) Dabrafenib in BRAF-mutated metastatic melanoma: a multicentre, openlabel, phase 3 randomised controlled trial. Lancet 380: 358-365.

Heinzerling L, Kuhnapfel S, Meckbach D, Baiter M, Kaempgen E, Keikavoussi P, Schuler G, Agaimy A, Bauer J, Hartmann A, Kiesewetter F, Schneider-Stock R (2013) Rare BRAF mutations in melanoma patients: implications for molecular testing in clinical practice. Br J Cancer 108: 2164-2171.

Hocker T, Tsao H (2007) Ultraviolet radiation and melanoma: a systematic review and analysis of reported sequence variants. Hum Mutat 28: 578-588.

Hodi FS, O'Day SJ, McDermott DF, Weber RW, Sosman JA, Haanen JB, Gonzalez R, Robert C, Schadendorf D, Hassel JC, Akerley W, van den Eertwegh AJ, Lutzky J, Lorigan P, Vaubel JM, Linette GP, Hogg D, Ottensmeier CH, Lebbe C, Peschel C, Quirt I, Clark JI, Wolchok JD, Weber JS, Tian J, Yellin MJ, Nichol GM, Hoos A, Urba WJ (2010) Improved survival with ipilimumab in patients with metastatic melanoma. $N$ Eng J Med 363: 711-723.

Hodis E, Watson IR, Kryukov GV, Arold ST, Imielinski M, Theurillat JP, Nickerson E, Auclair D, Li L, Place C, Dicara D, Ramos AH, Lawrence MS, Cibulskis K, Sivachenko A, Voet D, Saksena G, Stransky N, Onofrio RC, Winckler W, Ardlie K, Wagle N, Wargo J, Chong K, Morton DL, Stemke-Hale K, Chen G, Noble M, Meyerson M, Ladbury JE, Davies MA, Gershenwald JE, Wagner SN, Hoon DS, Schadendorf D, Lander ES, Gabriel SB, Getz G, Garraway LA, Chin L (2012) A landscape of driver mutations in melanoma. Cell 150: 251-263.

Jakob JA, Bassett Jr. RL, Ng CS, Curry JL, Joseph RW, Alvarado GC, Rohlfs ML, Richard J, Gershenwald JE, Kim KB, Lazar AJ, Hwu P, Davies MA (2012) NRAS mutation status is an independent prognostic factor in metastatic melanoma. Cancer 118: 4014-4023.

Jewell R, Chambers P, Harland M, Laye J, Conway C, Mitra A, Elliott F, Cook MG, Boon A, Newton-Bishop J (2012) Clinicopathologic features of V600E and V600K melanoma. Clin Cancer Res 18: 6792-6793.

Kim SY, Kim SN, Hahn HJ, Lee YW, Choe YB, Ahn KJ (2015) Metaanalysis of BRAF mutations and clinicopathologic characteristics in primary melanoma. J Am Acad Dermatol 72: 1036-1046.

Lang J, MacKie RM (2005) Prevalence of exon 15 BRAF mutations in primary melanoma of the superficial spreading, nodular, acral, and lentigo maligna subtypes. J Invest Dermatol 125: 575-579.

Lee JH, Choi JW, Kim YS (2011) Frequencies of BRAF and NRAS mutations are different in histological types and sites of origin of cutaneous melanoma: a meta-analysis. $\mathrm{Br} J$ Dermatol 164: 776-784.

Leiter U, Meier F, Schittek B, Garbe C (2004) The natural course of cutaneous melanoma. J Surg Oncol 86: 172-178.

Liu W, Kelly JW, Trivett M, Murray WK, Dowling JP, Wolfe R, Mason G, Magee J, Angel C, Dobrovic A, McArthur GA (2007) Distinct clinical and pathological features are associated with the BRAF(T1799A(V600E)) mutation in primary melanoma. J Invest Dermatol 127: 900-905.

Long GV, Menzies AM, Nagrial AM, Haydu LE, Hamilton AL, Mann GJ, Hughes TM, Thompson JF, Scolyer RA, Kefford RF (2011) Prognostic and clinicopathologic associations of oncogenic BRAF in metastatic melanoma. J Clin Oncol 29: 1239-1246.

Lovly CM, Dahlman KB, Fohn LE, Su Z, Dias-Santagata D, Hicks DJ, Hucks D, Berry E, Terry C, Duke M, Su Y, Sobolik-Delmaire T, Richmond A, Kelley MC, Vnencak-Jones CL, Iafrate AJ, Sosman J, Pao W (2012) Routine multiplex mutational profiling of melanomas enables enrollment in genotype-driven therapeutic trials. PLoS One 7: e35309.
Maldonado JL, Fridlyand J, Patel H, Jain AN, Busam K, Kageshita T, Ono T, Albertson DG, Pinkel D, Bastian BC (2003) Determinants of BRAF mutations in primary melanomas. J Natl Cancer Inst 95: 1878-1890.

Mar VJ, Wong SQ, Logan A, Nguyen T, Cebon J, Kelly JW, Wolfe R, Dobrovic A, McLean C, McArthur GA (2014) Clinical and pathological associations of the activating RAC1 P29S mutation in primary cutaneous melanoma. Pigment Cell Melanoma Res 27: 1117-1125.

Maxwell R, Garzon-Muvdi T, Lipson EJ, Sharfman WH, Bettegowda C, Redmond KJ, Kleinberg LR, Ye X, Lim M (2016) BRAF-V600 mutational status affects recurrence patterns of melanoma brain metastasis. Int $J$ Cancer 140: 2716-2727.

Meier F, Will S, Ellwanger U, Schlagenhauff B, Schittek B, Rassner G, Garbe C (2002) Metastatic pathways and time courses in the orderly progression of cutaneous melanoma. Br J Dermatol 147: 62-70.

Menzies AM, Haydu LE, Visintin L, Carlino MS, Howle JR, Thompson JF, Kefford RF, Scolyer RA, Long GV (2012) Distinguishing clinicopathologic features of patients with V600E and V600K BRAF-mutant metastatic melanoma. Clin Cancer Res 18: 3242-3249.

Mervic L (2012) Time course and pattern of metastasis of cutaneous melanoma differ between men and women. PLoS One 7: e32955.

Poynter JN, Elder JT, Fullen DR, Nair RP, Soengas MS, Johnson TM, Redman B, Thomas NE, Gruber SB (2006) BRAF and NRAS mutations in melanoma and melanocytic nevi. Melanoma Res 16: 267-273.

Reintgen DS, Cox C, Slingluff CL, Seigler HF (1992) Recurrent malignant melanoma: the identification of prognostic factors to predict survival. Ann Plast Surg 28: 45-49.

Ribas A, Hamid O, Daud A, Hodi FS, Wolchok JD, Kefford R, Joshua AM, Patnaik A, Hwu WJ, Weber JS, Gangadhar TC, Hersey P, Dronca R, Joseph RW, Zarour H, Chmielowski B, Lawrence DP, Algazi A, Rizvi NA, Hoffner B, Mateus C, Gergich K, Lindia JA, Giannotti M, Li XN, Ebbinghaus S, Kang SP, Robert C (2016) Association of pembrolizumab with tumor response and survival among patients with advanced melanoma. JAMA 315: 1600-1609.

Rubinstein JC, Sznol M, Pavlick AC, Ariyan S, Cheng E, Bacchiocchi A, Kluger HM, Narayan D, Halaban R (2010) Incidence of the V600K mutation among melanoma patients with BRAF mutations, and potential therapeutic response to the specific BRAF inhibitor PLX4032. J Transl Med 8: 67-67.

Shinozaki M, Fujimoto A, Morton DL, Hoon DS (2004) Incidence of BRAF oncogene mutation and clinical relevance for primary cutaneous melanomas. Clin Cancer Res 10: 1753-1757.

Smalley KS (2003) A pivotal role for ERK in the oncogenic behaviour of malignant melanoma? Int J Cancer 104: 527-532.

Soong S-J, Harrison RA, McCarthy WH, Urist MM, Balch CM (1998) Factors affecting survival following local, regional, or distant recurrence from localized melanoma. J Surg Oncol 67: 228-233.

Sosman JA, Kim KB, Schuchter L, Gonzalez R, Pavlick AC, Weber JS, McArthur GA, Hutson TE, Moschos SJ, Flaherty KT, Hersey P, Kefford R, Lawrence D, Puzanov I, Lewis KD, Amaravadi RK, Chmielowski B, Lawrence HJ, Shyr Y, Ye F, Li J, Nolop KB, Lee RJ, Joe AK, Ribas A (2012) Survival in BRAF V600-mutant advanced melanoma treated with vemurafenib. $N$ Engl J Med 366: 707-714.

Spittle C, Ward MR, Nathanson KL, Gimotty PA, Rappaport E, Brose MS, Medina A, Letrero R, Herlyn M, Edwards RH (2007) Application of a BRAF pyrosequencing assay for mutation detection and copy number analysis in malignant melanoma. J Mol Diagn 9: 464-471.

Tejera-Vaquerizo A, Barrera-Vigo MV, Fernandez-Canedo I, Blazquez-Sanchez N, Mendiola-Fernandez M, Fernandez-Orland A, Bosch-Garcia R, de Troya-Martin M, Herrera-Ceballos E (2007) Longitudinal study of different metastatic patterns in the progression of cutaneous melanoma. Actas Dermosifiliogr 98: 531-538.

Thomas NE, Edmiston SN, Alexander A, Groben PA, Parrish E, Kricker A, Armstrong BK, Anton-Culver H, Gruber SB, From L, Busam KJ, Hao H, Orlow I, Kanetsky PA, Luo L, Reiner AS, Paine S, Frank JS, Bramson JI, Marrett LD, Gallagher RP, Zanetti R, Rosso S, Dwyer T, Cust AE, Ollila DW, Begg CB, Berwick M, Conway K. Group GEMS (2015) Association between NRAS and BRAF mutational status and melanoma-specific survival among patients with higher-risk primary melanoma. JAMA Oncol 1: $359-368$.

Thomas NE, Edmiston SN, Alexander A, Millikan RC, Groben PA, Hao H, Tolbert D, Berwick M, Busam K, Begg CB, Mattingly D, Ollila DW, Tse CK, Hummer A, Lee-Taylor J, Conway K (2007) Number of nevi and early-life ambient UV exposure are associated with 
BRAF-mutant melanoma. Cancer Epidemiol Biomarkers Prev 16: 991-997.

Ugurel S, Thirumaran RK, Bloethner S, Gast A, Sucker A, Mueller-Berghaus J, Rittgen W, Hemminki K, Becker JC, Kumar R, Schadendorf D (2007) $\mathrm{B}-\mathrm{RAF}$ and N-RAS mutations are preserved during short time in vitro propagation and differentially impact prognosis. PLoS One 2: e236.

Viros A, Fridlyand J, Bauer J, Lasithiotakis K, Garbe C, Pinkel D, Bastian BC (2008) Improving melanoma classification by integrating genetic and morphologic features. PLoS Med 5: e120.

Voskoboynik M, Mar V, Mailer S, Colebatch A, Fennessy A, Logan A, Hewitt C, Cebon J, Kelly J, McArthur G (2016) Clinicopathological characteristics associated with BRAFK601E and BRAFL597 mutations in melanoma. Pigment Cell Melanoma Res 29: 222-228.

Willmore-Payne C, Holden JA, Tripp S, Layfield LJ (2005) Human malignant melanoma: detection of BRAF- and c-kit-activating mutations by highresolution amplicon melting analysis. Hum Pathol 36: 486-493.

This work is published under the standard license to publish agreement. After 12 months the work will become freely available and the license terms will switch to a Creative Commons AttributionNonCommercial-Share Alike 4.0 Unported License.

Supplementary Information accompanies this paper on British Journal of Cancer website (http://www.nature.com/bjc) 